\title{
Covid-19: why is the UK government ignoring WHO's advice?
}

\author{
Testing and tracing must resume urgently
}

\section{Allyson M Pollock professor of public health ${ }^{1}$, Peter Roderick principal research associate ${ }^{1}, \mathrm{KK}$ Cheng director ${ }^{2}$, Bharat Pankhania clinical senior lecturer ${ }^{3}$}

\begin{abstract}
${ }^{1}$ Population Health Sciences Institute, Faculty of Medical Sciences, Newcastle University, Newcastle, UK; ${ }^{2}$ Institute of Applied Health Research College of Medical and Dental Sciences, University of Birmingham, Birmingham, UK; ${ }^{3}$ College of Medicine and Health, University of Exeter, Exeter, UK
\end{abstract}

On 24 February, there were nine confirmed cases of covid-19 in the UK. On the same day, the World Health Organization recommended countries outside China with imported cases or outbreaks "prioritize active, exhaustive case finding and immediate testing and isolation, painstaking contact tracing and rigorous quarantine of close contacts."

On 22 March-when there were 5683 confirmed UK cases-Michael Ryan, executive director of the WHO health emergencies programme, repeated the message on the BBC: "What we really need to focus on is finding those who are sick, those who have the virus, and isolate them, find their contacts and isolate them."

This is entirely unexceptional. Case finding, contact tracing and testing, and strict quarantine are the classic tools in public health to control infectious diseases. WHO says they have been painstakingly adopted in China, with a high percentage of identified close contacts completing medical observation. In Singapore, Vietnam, and South Korea meticulous contact tracing combined with clinical observation plus testing were vital in containing the disease. This combined with strong measures to enforce isolation for travellers returning from high incidence areas obviated the need for a national lockdown and closure of all schools in Taiwan and Singapore. ${ }^{23}$

The mathematical model used by the UK government clearly shows that rigorous contact tracing and case finding is effective: ${ }^{4}$ the prediction of 250000 deaths was predicated on what would happen without contact tracing. 5

Contact tracing started in the UK but stopped early in the epidemic. ${ }^{6}$ How effective it was is questionable, especially in England and Wales, which made covid-19 a notifiable disease only on 5 March, ${ }^{78}$ two weeks after Scotland ${ }^{9}$ and a week after Northern Ireland. ${ }^{10}$ This, coupled with the lack of surveillance and testing of those contacting primary care, suggests the number of confirmed cases is an underestimate.
The reasons why tracing was stopped, against WHO recommendations, have not been published. It seems to be connected to a shift from "contain" to "delay" in the government's action plan, ${ }^{11}$ when contact tracing was replaced rather than supplemented with other control measures.

One reason seems to be a lack of tests and testing facilities. However, testing is a support not a substitute for tracing or medical observation, which is crucial. Current tests for the virus require careful validation and have low sensitivity, resulting in many false negative results, especially in the pre-symptomatic phase when viral load is low. As many as $40-50 \%$ of patients tested negative initially in China, and so the definition of confirmed cases was changed to include those with clinical symptoms. ${ }^{12} 13$

\section{Need for local response}

Another factor is the decision to treat the situation as a single national epidemic rather than scores of local outbreaks each at different stages, needing to be tackled locally. National figures conceal huge variation in confirmed cases, ranging from over 400 in Birmingham and Hampshire to fewer than 20 in Blackpool, Hartlepool, Darlington, and Rutland. In Scotland the first case was identified on 1 March, and Orkney and the Western Isles still have no cases.

In the much less severe H1N1 flu pandemic in 2009, this same approach "seriously impaired the ability of local agencies to respond in a flexible, timely and pragmatic way to the rapidly emerging situation." ${ }^{14}$

Matters have worsened since 2009. Central control in England was entrenched by the 2012 Health and Social Care Act, which created Public Health England (PHE) to protect the health of the public in England and gave local authorities the duty to improve the health of their local populations. PHE is legally in charge of communicable disease control and sits outside the NHS and local government in its regional hubs and field 
epidemiological services. Directors of public health in local authorities have little scope for proactively taking local control.

These changes are exacerbated by the decimation of public health and laboratory facilities for testing. The decrease in numbers of consultants in communicable disease control and community control teams, ${ }^{15}$ together with swingeing local authority cuts since 2010 , have reduced the chances of a strong local response. Local pathology and virology services have been centralised and partly privatised, leading to a fragmented mix of for-profit and public laboratories and serious staff shortages. ${ }^{16-19}$

\section{Listen to disease control evidence}

The scientific evidence has been dominated by behavioural science and mathematical modelling, with communicable disease control and public health sidelined. This leads to a lack of scientific challenge, as in the 2009 flu epidemic. ${ }^{20}$

So what now? WHO's mantra of "trace, test, and treat" must be followed. It is not too late to adopt WHO Guidance. ${ }^{2122} \mathrm{~A}$ second and third wave of the epidemic is likely. Contact tracing must recommence. This means immediately instituting a massive, centrally coordinated, locally based programme of case finding, tracing, clinical observation, and testing. It requires large teams of people, including volunteers, using tried and tested methods updated with social media and mobile phones and adapting the manuals and guidance published by China. ${ }^{234}$

The structure and capacity of our depleted healthcare system is now largely driving the response to this epidemic. It will continue to do so until services that support local communicable disease control are rebuilt and reintegrated.

Competing interests: We have read and understood BMJ policy on declaration of interests and declare BP is a former consultant in communicable disease control. Provenance and peer review: Commissioned; not externally peer reviewed.

1 World Health Organization. Report of the WHO-China Joint Mission on coronavirus disease 2019 (COVID-19), 16-24 February 2020. https://www.who.int/docs/default-source/ coronaviruse/who-china-joint-mission-on-covid-19-final-report.pdf

2 Wang $\mathrm{CJ}, \mathrm{Ng} \mathrm{CY}, \mathrm{Brook}$ RH. Response to COVID-19 in Taiwan: big data analytics, new technology, and proactive testing. JAMA 2020. 10.1001/jama.2020.3151. 32125371

$3 \mathrm{Ng} \mathrm{Y}, \mathrm{Li} Z$, Chua YX, etal . Evaluation of the effectiveness of surveillance and containment measures for the first 100 patients with COVID-19 in Singapore-January 2-February 29, 2020. MMWR Morb Mortal Wkly Rep 2020;69:307-11.

10.15585/mmwr.mm6911e1. 32191691
4 Keeling MJ, Hollingsworth TD, Read JM. The efficacy of contact tracing for the containment of the 2019 novel coronavirus (COVID-19). medRxiv 2020.02.14.20023036. [Preprint.] 2020. 10.1101/2020.02.14.20023036

5 Ferguson NM, Laydon D, Nedjati-Gilani G, et al. Impact of non-pharmaceutical interventions (NPIs) to reduce COVID19 mortality and healthcare demand. 16 Mar 2020. https://www. imperial.ac.uk/media/imperial-college/medicine/sph/ide/gida-fellowships/lmperial-CollegeCOVID19-NPI-modelling-16-03-2020.pdf

6 Coronavirus: Academy of Medical Sciences hold news briefing, 19 Mar 2020. https://www. youtube.com/watch?v=09jJz00szgU

7 The Health Protection (Notification). (Amendment) Regulations 2020. http://www.legislation. gov.uk/uksi/2020/237/made

8 The Health Protection (Notification) (Wales) (Amendment) Regulations 2020. http://www. legislation.gov.uk/wsi/2020/232/made

9 The Public Health etc. (Scotland) Act 2008 (Notifiable Diseases and Notifiable Organisms) Amendment Regulations 2020. www.legislation.gov.uk/ssi/2020/51/made

10 The Public Health Notifiable Diseases Order (Northern Ireland) $2020 \mathrm{http}: / / w w w . l e g i s l a t i o n$. gov.uk/nisr/2020/23/made

11 Department of Health and Social Care. Policy paper: coronavirus action plan: a guide to what you can expect across the UK. 3 Mar 2020. https://www.gov.uk/government/ publications/coronavirus-action-plan/coronavirus-action-plan-a-guide-to-what-you-canexpect-across-the-uk

12 Wang C, Liu L, Xingjie H. Evolving epidemiology and impact of non-pharmaceutical interventions on the outbreak of coronavirus disease 2019 in Wuhan, China. medRxiv medRxiv 2020.03.03.20030593 [Preprint.] 2020. 10.1101/2020.03.03.20030593

13 Covert coronavirus, chaos prize and the cost of contact-tracing. Nature 2020;579:477. 10.1038/d41586-020-00829-4 32214268

14 Chambers J, Barker K, Rouse A. Reflections on the UK's approach to the 2009 swine flu pandemic: conflicts between national government and the local management of the public health response. Health Place 2012;18:737-45 10.1016/j.healthplace.2011.06.005. 22682089

15 Centre for Workforce Intelligence. Review of the infection prevention and control nurse workforce. 2015. https://assets.publishing.service.gov.uk/government/uploads/system/ uploads/attachment_data/file/507608/CfWI Review_of IPC nurse workforce.pdf

16 UK Parliament. Cancer workforce and early diagnosis. House of Commons Hansard, 2019;652:col39WH. https://hansard.parliament.uk/Commons/2019-01-08/debates/ 277691ae-5e81-4b15-9e77-9eb20a6ed33b/WestminsterHall

17 Royal College of Pathologists. Testing for COVID-19. 24 Mar 2020. https://www.rcpath. org/discover-pathology/news/testing-for-covid-19.html.

18 Royal College of Pathologists. The Royal College of Pathologists' response to Lord Carter's report on operational productivity. 2016. https://www.rcpath.org/uploads/assets/be8ff23cc7c7-4b92-8c948a5980ad9f9f/RCPath-response-to-Carter-Review.pdf

19 Royal College of Pathologists. Pathology networks. 2017. https://www.rcpath.org/discover pathology/public-affairs/pathology-networks.html

20 Hine D. The 2009 influenza pandemic: an independent review of the UK response to the 2009 influenza pandemic. Cabinet Office, 2010. https://assets.publishing.service.gov.uk/ government/uploads/system/uploads/attachment_data/file/61252/ the2009influenzapandemic-review.pdf

21 WHO. Critical preparedness, readiness and response actions for COVID-19. https://www. who.int/emergencies/diseases/novel-coronavirus-2019/technical-guidance/criticalpreparedness-readiness-and-response-actions-for-covid-19

22 WHO. Coronavirus disease (COVID-19) technical guidance: laboratory testing for 2019-nCoV in humans (updated 2 Mar 2020). https://www.who.int/emergencies/diseases novel-coronavirus-2019/technical-guidance/laboratory-guidance

23 Chinese Center for Disease Control and Prevention. Covid19. http://www.chinacdc.cn/ en/COVID19/

24 McCarthy N. The countries with the most critical care beds per capita. Forbes 2020 Mar 12. https://www.forbes.com/sites/niallmccarthy/2020/03/12/the-countries-with-the-mostcritical-care-beds-per-capita-infographic/amp/.

Published by the BMJ Publishing Group Limited. For permission to use (where not already granted under a licence) please go to http://group.bmj.com/group/rights-licensing/ permissions 